\title{
A SECOND LOOK AT RETRIEVAL SYSTEMS
}

\section{Richard A. Spears, Northwestern University}

If there is not a raging controversy over retrieval $v s$ conventional laboratories, there should be.

In the NALLD JOURNAL, Vol. IV No. 1, pages 78-82, the Acoustron Corporation swung the balance decisively in favor of the "conventional laboratory" through exaggerate and invidious comparison of the two systems." Thus the issue is properly raised.

The article in question is "How Small or How Large: The Sensible Use of Touch-Tone Retrieval in Education." The argumentation presented within the article is what I wish to review and discuss. To promote a dialogue between laboratory designers and laboratory operators I offer this criticism in hopes that any future response might be constructive.

Here is a brief summary of the Acoustron article. After a discussion of the history of telephone switching and the development of the telephone dial and Touch-Tone $(\mathbb{R}$ systems, a hypothetical language learning situation is set up to show the virtues of the Touch-Tone $\mathbb{R}$ system over the conventional system. The advantages of Touch-Tone $\mathbb{R}$ over the standard dial are also mentioned.

"Unlike a dial which works on the rather primitive principle of turning the circuit on and off (like the kitchen light), the Touch-Tone unit generates tonal combinations that can be detected and used to operate not only telephone exchanges, but also computer processing units or your own private switching equipment."2

The hypothetical language learning situation is described as follows:

"One way of doing this would be to pass out a complete set of tapes to each student in the class. Thus, for 60 students there would be a need for perhaps ten or twenty dual-channel language laboratory recorders and 60 sets of material. The taped material

\footnotetext{
1The article dealt solely with the Acoustron Corporation's Touch-Tone retrieval system utilizing something like Western Electric's Touch-Tone @ transistorized, tone-generating keyboard switch assembly. My comments apply both to the dial and keyboard switch type of retrieval system. The conclusions suggested here are not intended to be substantive judgments on the relative value of different brands of dial and keyboard switch systems. ${ }^{2}$ NALLD JOURNAL, Vol. IV No. 1, p. 78.
} 
facility? Was it ill-desigred and equipped with gadgets that no one used, while lacking sensible, fur.ctional capabilities?

Please keep the last question in mind as you cortinue.

\section{The Hypothetical Problem}

To make the "conventional laboratory" unattractive, one can exaggerate the difficulties associated with the operation of such a facility. In this respect, the article in question cannot be surpassed. It seems the authors have so exaggerated the situation that their cost estimates of the solutions are ridiculously low.

Here is the problem as presented in the article.

1. There are 60 students.

2. There are 50-60 hours of recorded material for the course that the 60 students are taking.

3. Each student must be able to get at any part of the $50-60$ hours of recorded tape whenever and as often as he desires.

\section{Evaluation of the Hypothetical Problem.}

First, 50-60 hours ${ }^{6}$ of recorded material seems excessive. In a school year of 180 days, with the students having one period (50 minutes) per day for this course, it would require at least 72 class periods to listen to the material only one time. If one managed to get only 30 minutes of work in the laboratory per period 5 days per week, it would consume 120 of the 180 days to cover the 60 hours of recording. If the student dared review to the extent that he might master the material (arbitrarily 3 times through each lesson), he would not have enough time to "master" the entire course (three 50 minute hearings $\times 72=216$ days) in 180 days. This aspect of the problem is additionally unrealistic if a teacher is going to play any part in the learning process.

The third requirement in the hypothetical situation says that students must have access to any part of the 60 hours of recorded tape at "... any time they need them, throughout the course ..."7. But the first week, a student in a single course cannot really "need" hours 40-60, 20-60 or even 10-60. A few students (not all) might need to review lessons from the previous two or three weeks, but not all of the tapes, constantly. As pointed out above, there isn't time for that. The exception might be phonology tapes available throughout the course. The number of students needing hours 31-60 midway through the course is likely to be zero. If all 60 students still need hours 1-30, there is something wrong with the course.

6I choose the larger figure in the spirit of exaggeration.

IIbid. 
would include any supplementary recordings the teacher made any time during the course and would probably amount to about 50-60 hours of tape for a one year course. The problems associated with this method of disseminating audio recordings include the cost of duplication for a large number of language courses, the cumbersome handling of tape circulation and equipment use as well as the terrors of freely distributing several thousand reels of tape for students to mishandle, lose or rerecord with hard rock and folk songs.

An alternate to this is to provide some electro-mechanical device that will provide students with access to the right spot within a large number of always available tapes. This is where Touch-Tone selection is advantageous. It offers a student-operated selection device, that allows the student to decide what he wants to hear."3

Two possible objections to the Touch-Tone system are refuted. The first objection concerns a comparison of the costs of the Acoustron system and a conventional laboratory over a twelve year period. It is impossible to comment on this comparison because no specifications are given. The second objection is discussed in detail below.

I am put-off by being told that a dial (as opposed to the keyboard switch) works on the "... rather primitive principle of turning the circuit on and off (like the kitchen light) ..." First: keyboard switches contain many "rather primitive" on-and-off switches. The switch contacts are subject to the same ills as your kitchen light switch, plus

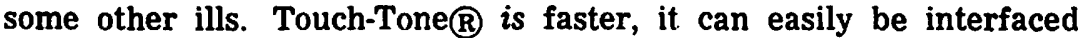
with a computer and you can still make a telephore call with a TouchTone $\mathbb{B}$ telephone even if someone has the receiver of the extension phone off the hook.

Second: is there any point in converting your satisfactorily-operating, rather primitive switching equipment (like the kitchen light) to tone-generating equipment if you do not anticipate connecting the system to a computer at some time within the life of the system?

The hasty brushing-over of the "forgotten" language laboratory 4 services neither students, laboratory manufacturers, teachers, laboratory directors, supervisors, nor taxpayers involved in "forgetting". Why was the laboratory forgotten? Was it participation in a fad? Was it poorly used?5 Was it so expensive that pressure was put on students and faculty to use it, resulting in human rejection of the 3op. cit. p. 80.

"It must, sadly, be observed that many laboratories haven't received such profit-" able usage, but the 'forgotten' language laboratory will not be considered here." NALLD JOURNAL, Vol. IV, No. 1, p. 78.

sIf this were a poll, "yes" answers would probably predominate. 
To justify the requirement that each of the 60 students must be able to retrieve any segment within the 60 hours of recorded tape, one would have to justify the use of that much recorded tape quite thoroughly. There doesn't seem to be time to use that much material effectively in 180 days.

\section{Solution I to the Hypothetical Problem}

The "unsatisfactory" solution given for the problem described above is a $10-20$ position dual-channel language laboratory and the production of 60 copies of all lesson material8. In that way, students would have access to the lessons at any time. (At least 10-20 students would.) The Acoustron article suggests that a complete set of tapes be passed out to each student in the class. Depending on the tape format used the cost of the tape alone would range from $\$ 8,100$. to $\$ 34,560$. (OR/ G/ NAt Sect $71 / 2$ )

Typical cost for $S \operatorname{cotch}(\mathbb{R}, 11 / 2$ mil/ "Tenzar"(A tape: $=1200$ f
$607^{\prime \prime}$ reels (60 hours) at $33 / 4$ ips at $\$ 2.25=\$ 135.00$ $\$ 135$. x 60 students $=\$ 8,100$.
120 7" reels
$\left(60\right.$ hours) at $7 \frac{1}{2}$ ips at $\$ 2.25=\$ 270.00$ $\$ 270.00 \times 60$ students $=\$ 16,200$.
$2407 "$ reels (60 hours) at $7 \frac{1}{2}$ ips at $\$ 1.60=\$ 384.00$ $\$ 384$. $\times 60$ students $=\$ 23,040$.

iofmiter

ppos'

If each lesson were 10 minutes long and each lesson were put on

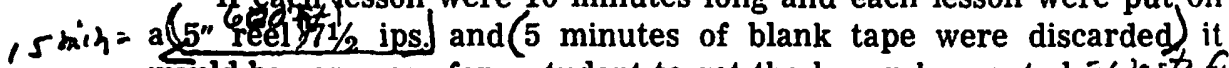
would be very easy for a student to get the lesson he wanted. = wask ful $3605^{\prime \prime}$ reels (60 hours) at $7 \frac{1}{2}$ ips at $\$ 1.60-\$ 576.00$ $\$ 576 . \times 60$ students $=\$ 34,560$.

Certainly, more than one high-speed (30-60 ips) duplicator would be needed to produce the copies. The $7^{\prime \prime}$ reels at $33 / 4$ ips $(\$ 8,100$.) might be chosen because of lower cost, but considering the systemconcept as a whole, there is no eviderce that good sense would prevail. I am assuming that the following functions would be available for the students.

1. Listen to a lesson or part of a lesson over and over.

2. Listen and respond as in (1).

3. Listen, record and compare as in (1).

The above three are to be performed on any sound or utterance repeatedly ad infinitum since the student would have total control of all functions of the tape deck which would be mounted in his carrel or elsewhere and remotely controlled from the carrel. Since each student would have a complete set of tapes, he could use them in the laboratory as well as at home (if he owned a tape player).

$\overline{8}$ One set of materials for each of the sixty students. Ibid. p. 80. 


\section{An Evaluation of Solution I}

If there are only 10-209 dual language laboratory recorders (as suggested in the Acoustron article), there is little point in having 60 copies of the sixty hours of tape. A maximum of 20 could be used at one time (1/180th of the total number of tapes). As shown above, all 60 hours are not likely to be needed at the same time because 60 students aren't likely to need something in each of the 60 hours of recordings every day. Even if they do, there is no need to have $\mathbf{4 0}$ extra sets of the 60 hours of lessons which could never be used because of the existence of only 20 positions. A maximum of twenty complete sets would suffice. $=$ if users id serwe oncer

To summarize, the hypothetical situation. the problem is unrealistic and Solution I, as opposed by Acoustron, is an unnecessarily exaggerated response.

\section{Solution II to the Hypothetical Problem}

Solution II consists of a laboratory equipped with a retrieval switching system capable of connecting 50 of the 60 students to 60 hours of available program sources. (In addition, each position would have to be equipped with a dual-channel language laboratory recorder to permit each student to capture a portion of a program for repeated listening or recording and comparing exercises.) ${ }^{10}$ Depending on the size of the segments of the 60 hours of tape and the number of tape tracks used by the program source machines, the cost of the equipment will vary greatly. The least expensive system on common use would probably be sixty 60-minute tapes on multi-track machines running at $33 / 4$ ips: e.g. 15 one-quarter track program machines. The most expensive would be 360 ten-minute tapes on one track running at $71 / 2$ ips: 360 program machines. (In both cases it is assumed that each lesson is 10 minutes long.) The latter could cost 20 times as much as the former, but there are numerous steps in between. I would like to examine the consequences of choosing either of these two extremes.

The fewer tracks used on the tape, the smaller the chance that one student may start a program machine for his program, and also start one (in the case of 2-track operation) or three (in case of 4-track operation) other programs at the same time. The fewer machines, the longer the program, the less time a student must wait for the program in progress to "come around again."

9I will talk of 20 positions hereafter. Ten is too few.

10This is not part of the Acoustron solution. I have added it to make the second solution as functionally equivalent to the first as possible. This is the only way a student in the retrieval system could have the complete control over the program that he would have in the conventional laboratory. 
The most unsatisfactory of these retrieval systems for the hypothetical problem would be 15 one-quarter-track machines, each containing 1 hour of program material per track. The reasons are:

1. A student wanting only the first 10 minutes of a tape would be properly served only if he is the first one to start the tape.

2. A student who wants any given segment of tape would be properly served if, when he connected himself to the proper channel, the tape were at or nearly at the particular segment he wanted.

3. A student wanting the last 10 minutes of a reel would have to wait 50 minutes before he gets to it, if he starts the tape, less if the tape is already in progress.

4. The student who wishes to repeat any sound, utterance or passage would have to wait 60 minutes before it "comes around again" unless he has had the foresight to record a master copy of it at his position. If he decides he has mastered the segment by repeating the lesson in question, he goes back to the program source. But it would be beyond the point that he disconnected himself from it and he would have to wait until it "comes around again" in order to continue his progress (unless he works for exactly one hour and someone else restarts the tape).

5. Given a situation where all of the program sources may be at different points in their 60-minute programs and 60 students have $\mathbf{3 0}$ minutes lab time in each of $\mathbf{1 8 0}$ school days to master, sequentially, 60 hours worth of a lesson material in 10-minute segments, it is possible with this retrieval system (despite its operating at the speed of light) for $3 / 4$ th" to hear the particular 10-minute segment they would seek. Their entire laboratory experience could be spent sitting 30 minutes a day waiting for the proper program to "come around again". The probability of this happening is extremely low. The probability that all students would experience such difficulties as described in Numbers $2-4$ above at some time is, however, very high.

A partial cure for this is to have the short segments on separate multi-track decks. Ninety 4-track decks would do the job for this situation. Then a student would wait a maximum of 10 minutes for the beginning of the tape to "come around again" and the material he hears while waiting will be relevant.

\footnotetext{
"One-fourth of the students would have to start the fifteen machines and would, presumably, eventually get the program they wanted.
} 


\section{Retrieval Systems}

If the four programs on one reel are not of uniform length, students may have to sit through periods of silence before the program begins again. This will not occur if 1-track sources are used.

\section{A Comparison of Solution I and Solution II}

If the concepts embodied in the two solutions underlie two labor. atories that perform the same functions equally well we can say that, in some sense, the laboratories are equivalent.

1. To get any record/compare, or total control of listen-only passages, the retrieval system equipment must be identical to the "conventional laboratory" plus switching and program source equipment. In neither case does the student have to record and compare. The purpose of each student's having his own machine is to permit him to control his program completely.

2. If a student can operate a tape recorder (remotely or in his carrel) he should be able to find what he wants in the reel of tape in $0-4$ or 5 minutes. This will put him ahead of the retrieval system in the majority of the laboratory sessions.

3. Other points of comparison can be extrapolated from the discussion above.

To my. way of thinking, Acoustron's solution to its unrealistic hypothetical problem isn't as satisfactory as the one which the "conventional laboratory" can provide. In creating a hypothetical situation designed to bring out the worst in the "conventional laboratory", they have created a beast that poses immense problems for their own system.12

The article goes on to refute two possible objections to retrieval systems. I will deal only with the second objection:

The second objection ... was that in attempting to reduce the initial costs of such systems the students are not provided with exclusive access to an individual program. This is true, but it is similar to the fallacious argument that classrooms should be replaced by individual tutors because the students are denied exclusive access to (i.e. the complete attention of) the teacher. There are just some things that cost too much money, and for most the use of a teacher-student ratio of $1: 1$ is just as far out of the question as is exclusive access to a taped program in a retrieval system given the current state-of-theart.13

12Either system could better handle a smaller number of hours of recordings, particularly if attention were paid to current demands.

13 Ibid, p. 82. 
My objections to the retrieval system do not center around the lack of exclusive access to a specific program. They deal with results of the lack of exclusive access to a program and the results of the lack of total control of the program once a student has found it.

"... that classrooms should be replaced by individual tutors because the students are denied exclusive access to ... the teacher."14

is not a fallacious argument. It is financially unrealistic in most cases. I have taught language classes with only one student, but I have never heard an argument favoring this as the norm. (I have been told that it is financially unreasonable, however.)

The basic objection that students don't get in on the beginning of a program (build-up drills, etc.) is not adequately refuted. The objection is true but it is similar to some fallacious argument. The fallacy exists in trying to promote soundly designed retrieval systems which will not do the tasks of "conventional laboratories".

I also want to refer to the "state-of-the-art". The art is foreignlanguage learning.15 We know more now than we did 10 years ago. Experience has shown how electronic equipment can be used effectively or ineffectively. When the Electronic state-of-the-art can't do what we want or can only do it at great expense, (more correlation of goals is necessary between the manufacturers and those using the laboratories) Acoustron has over-promoted and under-promoted what may be a very good system for some applications. They have overpromoted retrieval systems by describing their application to needs which could be better satisfied by other systems. They have underpromoted retrieval systems by not describing their proper and innovative implementation. Such misdirected attempts create rifts between laboratory manufacturers and laboratory purchasers. (The unsuspecting may actually purchase systems far too specialized and complex for their needs.) This money is wasted in a field such as education which is generally pleading for funds. More perceptive purchases may become prejudiced against systems which are promoted badly. They may overlook exciting possibilities for substantive improvements in language education.

Reflecting on the above, one may agree that poorly-executed promotion hurts all manufacturers, and imperceptive purchasing of ill-conceived systems (and the resultant dissatisfaction) ${ }^{16}$ impedes progress in language education.

\section{Ibid.}

15That includes teaching.

${ }^{16} \mathrm{~A}$ manufacturer may succeed in convincing the imperceptive purchaser that he should be happy with an ill-conceived system. This is not considered to be an advaicement for our side. Rather, it is evidence for the "uneducated state" of the educator. 


\section{Retrieval Systems}

It is most likely that either the retrieval system or the "conventional laboratory" could provide an equally satisfactory soluticn to the hypothetical problem above provided the problem be made more realistic. This writer is not, by the way, an opponent of retricval systems, but rather a supporter who does not wish to see an existing innovation acquire a bad reputation from misuse before its worthiness has been established.

NB (An improved understandirg of the goals of language teachers could be called for on the part of the manufacturers.) Better, what is required is an understanding by the manufacturer that there are many varieties of successful laboratory usage current in American education, and thus there must be a decided effort to accomodate the existing needs of language instruction.

\section{ABOUT THE AUTHOR:}

Professor Spears is Acting Chairman of the Department of Linguistics, and Director of the Language Laboratory at the University of Northwestern. 